\title{
Dutch Economic Value of Radium-223 in Metastatic Castration- Resistant Prostate Cancer
}

\author{
Michel L. Peters ${ }^{1}$ - Claudine de Meijer ${ }^{2} \cdot$ Dirk Wyndaele $^{3} \cdot$ Walter Noordzij $^{4}$. \\ Annemarie M. Leliveld-Kors ${ }^{5}$ Joan van den Bosch ${ }^{6}$ Pieter H. van den Berg ${ }^{7}$. \\ Agni Baka ${ }^{1} \cdot$ Jennifer G. Gaultney ${ }^{8}$ (i)
}

Published online: 2 September 2017

(c) The Author(s) 2017. This article is an open access publication

\begin{abstract}
Background The treatment of metastatic castration-resistant prostate cancer has changed with the introduction of radium-223, cabazitaxel, abiraterone and enzalutamide. To assess value for money, their cost effectiveness in patients with metastatic castration-resistant prostate cancer previously treated with docetaxel from the Dutch societal perspective was investigated.

Methods A cost-effectiveness analysis was conducted using efficacy, symptomatic skeletal-related event and safety data obtained from indirect treatment comparisons. Missing skeletal-related event data for cabazitaxel were
\end{abstract}

The original version of the article was revised due to retrospective open access order.

Presented at the European Cancer Congress on 27 September, 2015 in Vienna, Austria, at the International Society For Pharmacoeconomics and Outcomes Research 18th Annual European Congress on the 9 November, 2015 in Milan, Italy, and at the Nederlandse Vereniging voor Nucleaire Geneeskunde Meeting on the 20 May, 2016 in Eindhoven, The Netherlands.

Electronic supplementary material The online version of this article (doi:10.1007/s40258-017-0350-x) contains supplementary material, which is available to authorized users.

Jennifer G. Gaultney

jgaultney@mapigroup.com

1 Real World Strategy and Analytics, Mapi Group, Houten, The Netherlands

2 Bayer B.V., Mijdrecht, The Netherlands

3 Department of Nuclear Medicine, Catharina Ziekenhuis, Eindhoven, The Netherlands

4 Department of Nuclear Medicine and Molecular Imaging, University of Groningen, University Medical Centre Groningen, Groningen, The Netherlands conservatively assumed to be identical to radium-223. A Markov model combined these clinical inputs with Dutch-specific resource use and costs for metastatic castration-resistant prostate cancer treatment from a societal perspective. Total quality-adjusted life-years and costs in 2017 euros were calculated over a 5-year (lifetime) time horizon.

Results Radium-223 resulted in $€ 6092$ and $€ 4465$ lower costs and 0.02 and 0.01 higher quality-adjusted life-years compared with abiraterone and cabazitaxel, respectively, demonstrating dominance of radium-223. Sensitivity analyses reveal a 64\% (54\%) chance of radium-223 being cost effective compared with abiraterone (cabazitaxel) at the informal $€ 80,000$ willingness-to-pay threshold. Compared with enzalutamide, radium-223 resulted in slightly lower quality-adjusted life-years $(-0.06)$ and $€ 7390$ lower costs, revealing a $61 \%$ chance of radium-223 being cost effective compared with enzalutamide. The lower costs of radium-223 compared with abiraterone and enzalutamide are driven by lower drug costs and prevention of expensive skeletal-related events. Compared with cabazitaxel, the lower costs of radium-223 are driven by lower costs of the drug, administration and adverse events.

Department of Urology, University of Groningen, University Medical Centre Groningen, Groningen, The Netherlands

6 Department of Internal Medicine, Albert Schweitzer Ziekenhuis, Dordrecht, The Netherlands

7 Department of Internal Medicine, Tergooi Ziekenhuizen, Hilversum, The Netherlands

8 Real World Strategy and Analytics, Mapi Group, The Translation and Innovation Hub Building, 5th Floor, 80 Wood Lane, White City, London W12 OBZ, UK 
Conclusion Radium-223 may be a less costly treatment strategy offering similar gains in health benefits compared with abiraterone, cabazitaxel and enzalutamide in patients with metastatic castration-resistant prostate cancer previously treated with docetaxel from the Dutch societal perspective.

\section{Key Points for Decision Makers}

While offering similar health gains, radium-223 may be a less costly treatment strategy compared with abiraterone followed by cabazitaxel and enzalutamide in patients with metastatic castrationresistant prostate cancer previously treated with docetaxel.

The lower costs of radium-223 are mainly driven by lower drug costs and prevention of expensive symptomatic skeletal events.

\section{Introduction}

Castration-resistant prostate cancer (CRPC) is an incurable form of prostate cancer resistant to surgical or pharmaceutical castration that occurs when the disease progresses despite castration levels of androgens. It is termed metastatic CRPC (mCRPC) when the disease has developed (bone) metastases [1-4]. Morbidity from complications of these bone metastases, i.e. symptomatic skeletal-related events (SSEs) such as pathologic fractures, spinal cord compression and pain, greatly impairs the quality of life of patients with mCRPC [5].

The Dutch incidence rate of prostate cancer in 2014 was 119 new cases per 100,000 men (preliminary estimate). The 10-year prevalence in 2013 was 73,639 [6]. About 3800 patients per year are diagnosed with metastatic, hormonesensitive prostate cancer and despite hormonal therapy around $75 \%$ of these patients will progress to mCRPC, with the median time to progression ranging from 18 to 24 months [7]. These patients have a poor prognosis, and are expected to survive $\leq 19$ months [8]. The standard of care for mCRPC progressing on androgen deprivation therapy has traditionally been docetaxel, with few therapeutic options for patients progressing. The treatment landscape of mCRPC has changed with the introduction of cabazitaxel (CA), abiraterone acetate (AA), enzalutamide (EN) and radium-223 (Ra-223), expanding the number of treatment options available and providing several additional months of survival [9].

Radium-223 is licensed in Europe for the treatment of adult patients with CRPC with symptomatic bone metastases and no visceral metastases [10]. The efficacy and safety of Ra-223 have been evaluated in a doubleblind, randomised, multinational, phase III study of Ra-223 (ALSYMPCA) for the treatment of patients with mCRPC who had either received docetaxel previously or were unwilling or unfit to receive docetaxel. Patients included in the trial were required to have two or more bone metastases detected on skeletal scintigraphy, a life expectancy of at least 6 months and no known visceral metastases or a malignant lymphadenopathy more than $3 \mathrm{~cm}$ in diameter. In the ALSYMPCA trial, Ra-223 improved the median overall survival (OS) by 3.6 months (hazard ratio $=0.695$; $p<0.001)$ and prolonged the median time to SSE by 5.8 months (hazard ratio $=0.658 ; p<0.001$ ) compared with placebo [11]. In the ALSYMPCA trial, the quality-oflife benefit associated with Ra-223 was greatest in the stable disease and pre-SSE setting, suggesting that delaying the occurrence of the first SSE is associated with a better quality of life $[12,13]$.

With the approval of new therapies, the costs of the management of mCRPC are increasing. Although the OS benefit of these innovative drugs has been well investigated, little is known about their cost effectiveness. Given the significant costs, the impact of SSEs on quality of life and the differences in SSE rates between treatments, an economic evaluation of the treatment landscape of patients with mCRPC with prior docetaxel treatment is warranted [5, 11-16]. KWF Kankerbestijding recently reported on the problems surrounding the financing of new cancer treatments and highlighted the importance of costs and of insight into the cost effectiveness of new treatments [17]. This study focuses purely on the post-docetaxel setting of mCRPC on account of the potential to introduce an unacceptable risk of bias when pooling data across patient populations studied in the docetaxel-naive setting of the trials for AA, EN and Ra-223, which differed significantly in terms of disease severity and prognosis. The aim of this study was to investigate the cost effectiveness of Ra-223 compared with $\mathrm{CA}, \mathrm{AA}$ and $\mathrm{EN}$, all in combination with the best standard of care, in patients with mCRPC previously treated with docetaxel from the Dutch societal perspective.

\section{Methods}

\subsection{Patient Population}

Patients with mCRPC despite prior docetaxel treatment as treated in the ALSYMPCA trial were the focus of this study. The baseline characteristics of these patients have been described elsewhere [11]. 


\subsection{Comparative Treatment}

The choice of comparators was based on a systematic literature review of the latest clinical trials in $\mathrm{MCRPC}$ and the Dutch guideline for mCRPC in the post-docetaxel setting, and was validated by experts in the MCRPC treatment field [3]. Only comparators that, like Ra-223, have a proven effect on OS and are recommended for systemic therapy for mCRPC in the post-docetaxel setting, were included in the model. Other treatments such as samarium-153EDTMP, strontium-89-chloride and rhenium-188-HEDP are only recommended for the treatment of pain (i.e. best supportive care) as they do not have a proven effect on OS [3]. In the systematic literature review, MEDLINE, MEDLINE In-Process, EMBASE and the Cochrane Library were searched in January 2014 [see Electronic Supplementary Material (ESM) for search details]. The search was restricted to records published from January 2000 onwards. Study selection took place based on predefined criteria regarding the population, interventions, outcomes and study design of interest. The population of interest consisted of adult patients with CRPC. The interventions of interest were Ra-223, AA, CA, EN, sipuleucelT, docetaxel, best supportive care, strontium-89, samarium-153, sunitinib, zibotentan, mitoxantrone and denosumab. Randomised controlled trials reporting clinical, quality of life, resource use and work productivity outcomes were of interest.

In the model, three comparisons were conducted: (1) Ra-223 vs. AA; (2) Ra-223 vs. CA; and (3) Ra-223 vs. EN. All comparators were administered in combination with best standard of care. The definition of best standard of care was based on the control arm of the ALSYMPCA trial and includes local external beam radiation, corticosteroids, antiandrogens, oestrogens (e.g. stilboestrol), estramustine or ketoconazole [11].

\subsection{Analytic Specifications and Model Structure}

A cost-utility analysis from the Dutch societal perspective including direct healthcare costs, direct non-medical costs of informal care and indirect costs owing to productivity loss was designed to estimate the costs and health outcomes incorporating improvements in the quality of life on survival. A cost-utility analysis was chosen given the impact of SSEs on quality of life and the differences in SSE rates between the selected comparators [5, 11-16]. In line with best practice for oncology modelling and the clinical trial, a Markov model was built to capture the transition of patients with mCRPC through clinically meaningful health states along the disease management pathway. The model was validated in accordance with the AdViSHE validationassessment tool [18] (see ESM). The model structure and input data were validated for the Dutch clinical perspective by four clinical experts treating daily practice patients in the Netherlands; similarly, the model outcomes were validated by six other clinical experts also treating daily practice patients in the Netherlands. A time horizon of 5 years was employed, which can be considered lifetime, given the short life expectancy of the patient population. Five health states are included: (1) progression-free survival (PFS) without SSE; (2) PFS with SSE; (3) progressed without SSE; (4) progressed with SSE; and (5) death (Fig. 1). Prostate-specific antigen levels were used to measure disease progression, defined as an increase of $\geq 25 \%$ from baseline level at $\geq 12$ weeks in patients with no decrease from baseline; or an increase of $\geq 25 \%$ in the level above the nadir, confirmed $\geq 3$ weeks later in patients with an initial decrease from baseline [11]. A SSE was defined as a pathologic bone fracture, spinal cord compression, external beam radiation or surgical intervention. Transitions between states occur within a cycle length of 1 week.

Patients enter the model in the 'PFS without SSE' health state and over time either remain in this state or transition to 'PFS with SSE', 'progressive without SSE', 'progressed with SSE' or 'death' in a later stage. Once a patient experiences an event of progression or SSE, it is not possible to transition back to the previous state. Therefore, patients in the 'PFS with SSE' will either remain in this state or transition to 'progressed with SSE' or 'death', and patients in the 'progressed without SSE' will either remain in this state or transition to 'progressed with SSE' or 'death'. Finally, patients in the 'progressed with SSE' may only remain in this state or transition to 'death'.

\subsection{Clinical Inputs}

Efficacy and safety data for Ra-223, AA, CA and EN were based on the ALSYMPCA, COU-AA-301, TROPIC and AFFIRM trials, respectively $[11,14-16]$. Transition

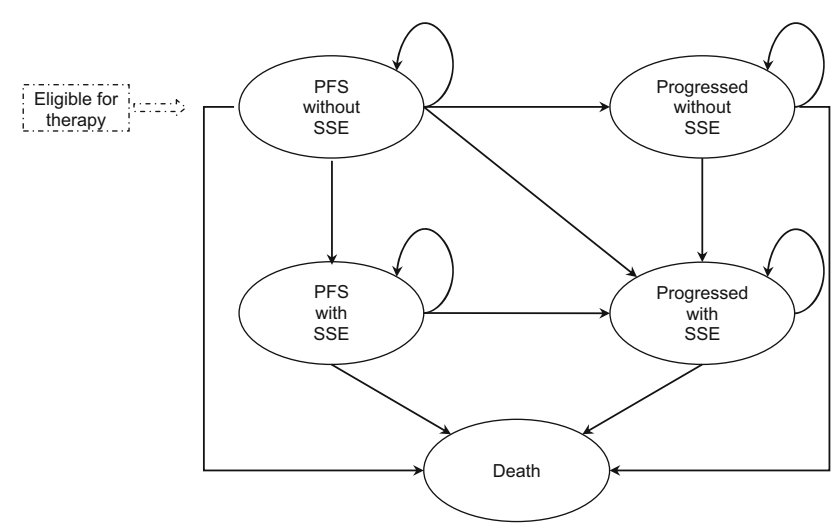

Fig. 1 Markov model structure. PFS progression-free survival, SSE symptomatic skeletal-related event 
probabilities for movement between health states for $\mathrm{Ra}$ 223 were based on patient-level data from the ALSYMPCA trial, specifically the OS, PFS and SSE eventfree survival data [11]. Clinical data were extrapolated beyond the period of the trial. Data from Kaplan-Meier curves were used to formulate different survivor functions, representing the risk of death, progression or SSE event over time (see ESM for details on the survival analysis methods). To select the appropriate distribution for the survival curves, three proportional hazard rate functions (i.e. Exponential, Gompertz and Weibull), and two accelerated-failure-time functions (i.e. Log-Logistic and LogNormal) were fitted to the Kaplan-Meier curves from both treatment arms. As visual inspection of the curves may be inaccurate, the Akaike Information Criterion was used to determine which parametric curve better fits the KaplanMeier data. The log-normal distribution was fitted to the Kaplan-Meier curves for OS and PFS both in the placebo (best standard of care) and Ra-223 arms based on goodness-of-fit tests using the lowest Akaike Information Criterion. For the incidence of SSE, which was based on SSE event-free survival, the best fit was the log-logistic distribution. To define the parametric survival model beyond the duration of the trial, the parameters of each fitting curve were extrapolated. As no patient-level data were available for the selected comparators for treatment of patients with mCRPC, data on hazard ratios for OS and PFS reported in the trials studying the selected comparators vs. BSC were obtained by means of a systematic literature review. For SSE event-free survival, there were no hazard ratios available in the systematic literature review and therefore a conservative assumption was made that the extrapolated SSE event-free survival was similar across the comparators and equal to that for Ra-223. Comparative effectiveness in terms of OS and PFS between the intervention and comparators was performed by evidence synthesis methods based on the common treatment arm BSC. An indirect treatment comparison by means of a Bayesian network meta-analysis was performed in WinBUGS on the hazard ratio for OS and PFS (see ESM for details on the network meta-analysis methods). The hazard ratios were applied to the parametric functions chosen for $\mathrm{Ra}-223$ to derive the transition probabilities for the selected comparators. Given the impossibility to apply a hazard ratio to the PFS curves based on the alkaline phosphatase test (log-normal and loglogistic), the use of the Weibull form was chosen as the most appropriate for comparisons of OS and PFS to other active agents as it is the best fitting curve by means of the Akaike Information Criterion among the proportional hazard rate functions. All clinical inputs can be found in the ESM.

Active treatment dosing was obtained from the respective summaries of product characteristics for Ra-223, AA,
CA and EN. Patients treated with Ra-223 and CA were assumed to receive in total five and six injections, respectively, in line with the mean treatment duration observed in the respective phase III studies [15, 19]. Symptomatic skeletal-related event data related to Ra-223, $\mathrm{AA}$ and EN were obtained from the respective pivotal trials (Table 1) [20-22]. As SSE data related to CA were not available, these were conservatively assumed to be identical to $\mathrm{Ra}-223$.

\subsection{Utility Inputs}

Health-state utilities for Ra-223 were derived directly from the health-related quality-of-life data collected in the ALSYMPCA trial (see the ESM) [11]. Utility data for AA, $\mathrm{CA}$ and $\mathrm{EN}$ were not available in the literature; therefore, these were conservatively assumed to be identical to those for Ra-223. In the trial, patients were asked to complete the EQ-5D at the baseline visit and at all the follow-up visits. Scores from each EQ-5D category were used to create a single utility index score using population-specific weights (UK population weights). Health-state utilities used in the model are assumed to reflect disutilities from adverse events patients experienced during the trial. Therefore, including additional disutilities for adverse events may result in double counting and their exclusion was considered a conservative assumption given the better safety profile of Ra-223 compared with AA, CA and EN $[11,14-16]$. This better safety profile is also reflected in the higher European Society for Medical Oncology Magnitude of Clinical Benefit Scale for Ra-223 than for AA, CA and EN [23].

\subsection{Resource Use and Cost Inputs}

Three cost categories were considered: (1) direct medical costs inside the health system, including drug acquisition costs, outpatient and inpatient visits costs, treatment administration, monitoring and adverse event management costs, and costs of treating SSEs; (2) direct non-medical costs outside the healthcare system, including informal caregiver costs; and (3) indirect non-medical costs, including productivity loss (see the ESM). All costs were inflated to 2017 euros using inflation rates published by Statistics Netherlands [24].

Resource use data specific to the Dutch clinical setting were gathered from Dutch hospital treatment protocols and during an advisory board with key opinion leaders in the field of treatment for mCRPC. Four clinical experts in the fields of oncology, urology and nuclear medicine participated in the advisory board on 18 September, 2014 During the advisory board, 20 specific questions were discussed; consensus on these questions was reached through deliberation. The 
Table 1 Frequency and costs of treating symptomatic skeletal-related events (SSEs) per comparator [20-22, 30]

\begin{tabular}{|c|c|c|c|c|c|}
\hline \multirow[t]{2}{*}{ SSE } & \multicolumn{4}{|c|}{ Incidence of SSE and type of SEE conditional on having any SSE (\%) } & \multirow{2}{*}{$\begin{array}{l}\text { Dutch SSE treatment } \\
\operatorname{costs}^{\mathrm{a}}(€)\end{array}$} \\
\hline & $\begin{array}{l}\mathrm{Ra}-223 \\
{[20]}\end{array}$ & CA & $\begin{array}{l}\text { AA } \\
{[21]}\end{array}$ & $\begin{array}{l}\text { EN } \\
{[22]}\end{array}$ & \\
\hline Incidence of SSE & \multicolumn{4}{|c|}{$\begin{array}{l}\text { Incidence of SSEs was based on Kaplan-Meier curve extrapolations of SSE free survival } \\
\text { data and assumed the same across all comparators owing to a lack of data }\end{array}$} & \\
\hline Recurrence of SSE ${ }^{\mathrm{b}}$ & 100 & & 100 & 100 & \\
\hline \multicolumn{6}{|c|}{ Distribution of SSE type } \\
\hline $\begin{array}{l}\text { Pathologic bone } \\
\text { fracture }\end{array}$ & 13 & $\begin{array}{l}\text { In absence of data, conservatively assumed to be equal to } \\
\text { Ra-223 }\end{array}$ & 15 & 11 & 14,358 \\
\hline $\begin{array}{l}\text { Spinal cord } \\
\text { compression }\end{array}$ & 10 & & 19 & 24 & 10,960 \\
\hline $\begin{array}{l}\text { External beam } \\
\text { radiation }\end{array}$ & 73 & & 61 & 63 & 2171 \\
\hline Surgical intervention & 5 & & 4 & 2 & 19,896 \\
\hline
\end{tabular}

$A A$ abiraterone acetate, $C A$ cabazitaxel, $E N$ enzalutamide, $R a-223$ radium-223

${ }^{a}$ Costs were taken from Carter et al. [30] and inflated to 2017 euros using inflation rates published by Statistics Netherlands [24]

b Probability of recurrence was assumed to be $100 \%$ based on expert opinion that all patients with an SSE will have a recurrence

advisory board resulted in a consensus report that was approved by all participants. In addition, resource use data were gathered in an interview with an expert involved in the Castration-resistant Prostate Cancer Registry, a real-world outcomes database in the Netherlands. In the case of important differences, the average of the data gathered from the advisory board and from the Castration-resistant Prostate Cancer Registry was used [25].

The number of physician outpatient visits and visits for monitoring procedures was calculated based on expert opinion elicited during the advisory board. Unit costs for drug acquisition, administration including outpatient visits, monitoring procedures, including computed tomography scan and laboratory tests were retrieved from published sources [26-28], validated by Dutch key opinion leaders in the field of mCRPC treatment and conform to the Dutch guidelines on cost research [28].

Healthcare utilisation associated with adverse event management, including the proportion of patients requiring hospitalisation and unit costs, was based on the ALSYMPCA trial for Ra-223 and the local reimbursement submission dossier for AA or on expert opinion when no data were available [29]. The costs related to the treatment of SSEs were obtained from Carter et al. [30]. It was assumed that $39 \%$ of patients required end-of-life care (i.e. hospice) based on Meeussen et al. with an average duration of 3 months based on expert opinion [31]. The remaining $61 \%$ were assumed to require daily visits by a nurse based on Meeussen et al., with an average duration of 3 months based on expert opinion [31].

The direct non-medical costs included in the model were informal caregiver costs. Other direct non-medical costs such as travel expenses were not included in the model, as no relevant differences in travel costs were expected between treatment groups based on expert opinion. Travel expenses are also minor in comparison to direct medical costs and are therefore assumed to have a negligible impact on the model results. Indirect costs owing to productivity loss are included in the model based on expert opinion and were calculated by means of the friction cost method as required by the Dutch guidelines [28, 32].

\subsection{Outcomes}

The main outcomes of the cost-utility analysis included total and incremental costs, health benefits in terms of total and incremental quality-adjusted life-years (QALYs) and life-years (LY) gained, and incremental cost-effectiveness ratios (ICERs). The ICERs were calculated as the difference in total costs between Ra-223 and selected comparators divided by the difference in the number of QALYs or the difference in LYs, resulting in the incremental cost per QALY and LY gained, respectively. Total costs and health benefits were discounted at 4 and $1.5 \%$, respectively, according to Dutch guidelines [32].

\subsection{Sensitivity Analysis}

A one-way sensitivity analysis was conducted to assess the impact of varying model inputs on the ICER. The parameters included in the one-way sensitivity analysis were: parameters of the parametric survival curves for OS and PFS, utility inputs, duration of therapy, cost items, discount rates for costs and outcomes and time horizon. A probabilistic sensitivity analysis (PSA) was also performed to 
assess the joint uncertainty of all parameters on the costeffectiveness results. The PSA was conducted by running 1000 simulations and applying the willingness-to-pay threshold at $€ 80,000$ per QALY gained, the informal proposed Dutch threshold for diseases of high severity [33]. The following parameters were analysed in the PSA: parameters of the parametric survival curves for OS and PFS (lognormal distribution), utility inputs (beta distribution), duration of therapy (gamma distribution), and the costs of treating adverse events grade 3 and 4 (gamma distribution) and SSEs (gamma distribution). The upper and lower distribution values can be found in the ESM.

\section{Results}

\subsection{Health Benefits}

Over the 5-year (lifetime) time horizon of the model, Ra223 yielded a total of 0.8 QALYs and 1.39 LYs. In comparison, AA yielded 0.78 QALYs and $1.36 \mathrm{LYs}$, CA yielded 0.79 QALYs and 1.38 LYs, and EN yielded 0.86 QALYs and 1.50 LYs (Table 2). Ra-223 was associated with fewer SSEs than AA and with fewer severe SSEs than EN (Table 1).

\subsection{Costs}

Compared with AA, Ra-223 accrued €6092 lower lifetime costs (Table 2). The lower costs of Ra-223 compared with those of AA are driven by lower drug and SSE treatment costs (Fig. 2). The lower costs for SSEs are associated with a lower frequency of more severe, and hence more costly, SSEs in Ra-223- than in AA-treated patients.

Compared with CA, Ra-223 accrued $€ 4465$ lower lifetime costs over the 5-year (lifetime) time horizon of the model (Table 2). The lower costs of Ra-223 compared with those of $\mathrm{CA}$ are driven by lower drug, administration and adverse event costs (Fig. 2).Taking into account that the SSE rates were assumed to be identical for Ra-223 and CA, the lower costs achieved with Ra-223 could be underestimated.

Compared with EN, Ra-223 accrued $€ 7390$ lower lifetime costs (Table 2). The lower costs of Ra-223 compared with those of EN are driven by lower drug and SSE treatment costs (Fig. 2). The latter is associated with a lower frequency of more severe, and hence more costly SSEs in Ra-223- than in EN-treated patients.

\subsection{Incremental Costs per Health Gain}

Ra-223 dominates AA followed by CA, with lower costs and higher QALYs and LYs. Compared with EN, Ra-223 was slightly less effective but also less costly (Table 2)

\subsection{One-Way Sensitivity Analysis}

The results of the one-way sensitivity analysis demonstrate that, across all comparisons, the most influential parameters include the hazard ratio for OS, duration of therapy, utility for 'progressed without SSE', non-medical costs (i.e. productivity costs and informal care), the cost of managing spinal cord compression and the utility for 'PFS without SSE' (see the ESM).

\subsection{Probabilistic Sensitivity Analysis}

At a willingness-to-pay threshold of $€ 80,000$, the PSA reveals a 54\% chance of Ra-223 being cost effective compared with CA, a $64 \%$ chance compared with AA and a $61 \%$ chance compared with EN (Fig. 3).

\section{Discussion}

This study shows that in the post-chemotherapy setting the effectiveness of Ra-223, in terms of QALYs and LYs, is comparable to CA, AA and EN. This is in line with the Dutch criteria assessing the value of new oncolytic medicines, showing that there is no clinically meaningful difference in the efficacy of Ra-223, AA, CA and EN $[33,34]$. The lifetime costs of patients with $\mathrm{mCRPC}$ in the Netherlands are lower for Ra-223 than for its comparators, mainly driven by lower drug and SSE costs. Therefore, Ra223 may be a less costly treatment strategy compared with $\mathrm{AA}, \mathrm{CA}$ and EN in Dutch patients with mCRPC previously treated with docetaxel.

This is the first study to investigate the cost effectiveness of Ra-223 compared with AA, CA and EN in the postdocetaxel setting in the Netherlands. The results reported here provide valuable insights that can inform decisions on the reimbursement of these medications in the Netherlands and on the allocation of oncology budgets within hospitals and healthcare insurers.

To compare with previous studies, a systematic search of the literature was performed identifying one full-text publication describing economic evaluations for AA, CA and/or EN in the post-docetaxel setting of mCRPC [35]. However, as the study by Zhong et al. employed an 18-month time horizon, compared with a lifetime time horizon in this study, no comparison of the results can be made. Fifteen conference abstracts describing such analyses were additionally identified [36-50], but as these only provide limited data and barely any information on the methods employed, no informed comparisons with the results from this study can be made.

The results of this study can nonetheless be compared with those reported for AA and CA in the Dutch 
Table 2 Results for costs and health benefits per comparison

\begin{tabular}{|c|c|c|c|c|c|c|c|}
\hline $\begin{array}{l}\text { Intervention } \\
\text { and } \\
\text { comparators }\end{array}$ & $\begin{array}{l}\text { Discounted } \\
\text { costs }(€)\end{array}$ & $\begin{array}{l}\text { Incremental costs } \\
{[\text { Ra-223 vs. }} \\
\text { comparator] }(€)\end{array}$ & $\begin{array}{l}\text { Discounted } \\
\text { LYs }\end{array}$ & $\begin{array}{l}\text { Incremental LYs } \\
\text { [Ra-223 vs. } \\
\text { comparator] }\end{array}$ & $\begin{array}{l}\text { Discounted } \\
\text { QALYs }\end{array}$ & $\begin{array}{l}\text { Incremental } \\
\text { QALYs [Ra-223 } \\
\text { vs. comparator] }\end{array}$ & $\begin{array}{l}\text { Incremental cost } \\
\text { per QALY }\end{array}$ \\
\hline Ra-223 & 78,318 & - & 1.39 & - & 0.8 & - & \\
\hline AA & 84,410 & -6092 & 1.36 & 0.03 & 0.78 & 0.02 & $\begin{array}{l}\text { Ra-223 dominates } \\
\text { AA }\end{array}$ \\
\hline $\mathrm{CA}$ & 82,783 & -4465 & 1.38 & 0.01 & 0.79 & 0.01 & $\begin{array}{l}\text { Ra-223 dominates } \\
\text { CA }\end{array}$ \\
\hline EN & 85,708 & -7390 & 1.5 & -0.11 & 0.86 & -0.06 & $\begin{array}{l}\text { Ra-223 slightly } \\
\text { less effective and } \\
\text { less costly }\end{array}$ \\
\hline
\end{tabular}

Costs are displayed in 2017 euros

$A A$ abiraterone acetate, $C A$ cabazitaxel, $E N$ enzalutamide, $L Y$ life-year, $Q A L Y$ quality-adjusted life-year, $R a-223$ radium-223

Fig. 2 Lifetime costs breakdown per comparison. $A A$ abiraterone acetate, $A E$ adverse event, $C A$ cabazitaxel, $E N$ enzalutamide, $m C R P C$ metastatic castration-resistant prostate cancer, $R a-223$ radium223, SSE symptomatic skeletalrelated event. Costs are displayed in 2017 euros

Fig. 3 Cost-effectiveness acceptability curves per comparison. $A A$ abiraterone acetate, $C A$ cabazitaxel, $E N$ enzalutamide, $Q A L Y$ qualityadjusted life-year, $R a-223$ radium-223. Costs are displayed in 2017 euros
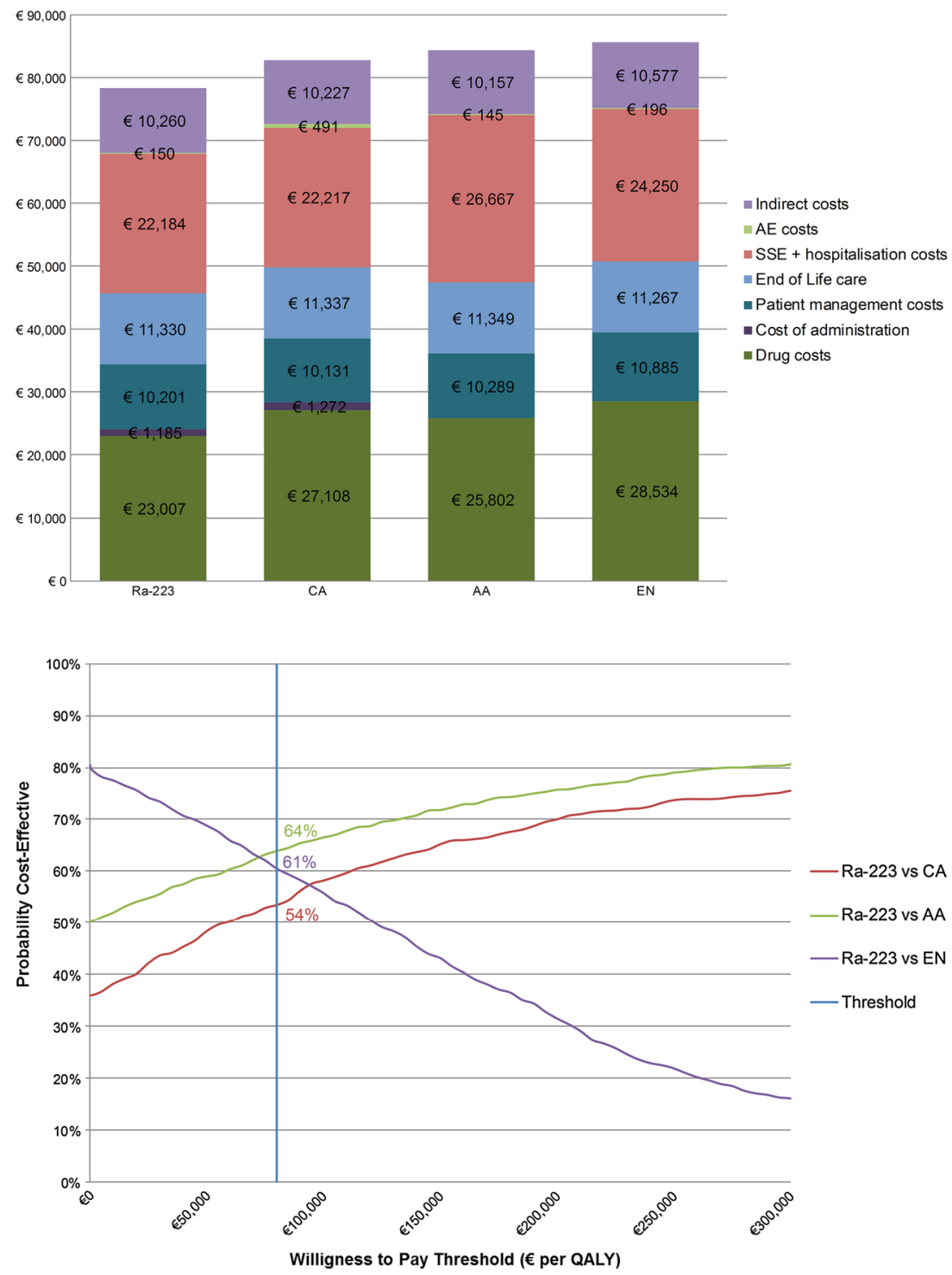
reimbursement process for mCRPC treatments. In 2011, the Dutch National Health Care Institute advised that CA can be added to the policy regulation expensive medications for the treatment of mCRPC that progresses on docetaxel [51]. The included pharmacoeconomic evaluation compared the cost effectiveness of CA with mitoxantron from a societal perspective over a lifetime time horizon. Treatment with CA yielded 1.5 LYs and 0.864 QALYs with an associated cost of $€ 46,247$ (in 2011 euros) per patient [51]. This result is comparable to the $1.38 \mathrm{LYs}, 0.79$ QALYs and $€ 82,783$ cost (in 2017 euros) that CA yielded in this study.

More recently, in 2012, the Dutch National Health Care Institute assessed AA and determined it to have equal therapeutic value to CA with higher expected costs. This normally would have resulted in a negative advice. However, the European Medicines Agency regarded AA as a valuable new therapy, and the mCRPC market was still changing after the positive assessment of $\mathrm{CA}$, resulting in a more uncertain cost estimate. Therefore, the Dutch National Health Care Institute advised reimbursement of AA for the treatment of mCRPC with disease progression despite previous docetaxel treatment [29]. The included pharmacoeconomic evaluation compared the cost effectiveness of AA plus prednisone with $\mathrm{CA}$ plus prednisone and prednisone monotherapy from a healthcare perspective over a lifetime time horizon. Treatment with AA yielded 1.41 LYs and 1.1 QALYs with an associated direct medical cost of $€ 37,297$ (in 2010 euros) per patient. Treatment with CA yielded $1.34 \mathrm{LYs}$ and 1.03 QALYs with an associated direct medical cost of $€ 32,915$ (in 2010 euros) per patient [29]. The result in LYs is comparable to the $1.46 \mathrm{LYs}$ for AA and 1.38 LYs CA yielded in this study. However, the QALYs differ from the 0.78 QALYs for AA and 0.79 QALYs for CA in this study. This can be explained by the use of higher health states utility values in the analysis submitted in the pharmacoeconomic dossier for AA ( 0.80 for baseline and 0.715 for post-progression) compared with this study (0.617 and 0.511 , respectively). No comparison of costs can be made owing to the difference in analysis perspective, i.e. healthcare vs. societal perspective. Finally, no report has been published for EN by the Dutch National Health Care Institute.

Regarding reimbursement decisions outside the Netherlands, the National Institute for Health and Care Excellence recently recommended Ra-223 in the UK as an option for treating adults with mCRPC and no known visceral metastases in the post-docetaxel setting under a patient access scheme. For patients who had previously received docetaxel, the committee concluded that the ICER for Ra-223 compared with AA fell within the acceptable range, with $\mathrm{Ra}-223$ dominating $\mathrm{AA}$ in the base-case analysis, and that Ra-223 could be considered cost effective $[52,53]$.
The National Institute for Health and Care Excellence has expanded the treatment scope based on an updated cost-effectiveness analyses performed by Bayer comparing Ra-223 with the current care available for people contraindicated for docetaxel, and for whom docetaxel is unsuitable and concluded that the use of Ra-223 is cost effective in this pre-docetaxel setting [49]. In the Netherlands, first-line use of Ra-223 in a pre-docetaxel setting is included in the recommendations for chemotherapy-fit and chemotherapy-unfit patients with mCRPC with symptomatic bone metastases and no visceral metastases [50].

A few limitations to the study methods deserve mentioning. First, the analysis is limited to the post-docetaxel setting of mCRPC on account of important differences between the patient populations in the docetaxel-naive setting of the trials for AA, CA, EN and Ra-223 in terms of disease severity and prognosis. Pooling these data in a modelling study would introduce an unacceptable risk of bias. However, the docetaxel-naive setting is also of interest and therefore further research into the cost effectiveness of AA, EN and Ra-223 in the docetaxel-naive setting of mCRPC is warranted.

Second, the results from this study are derived from patients treated in a trial setting, which may not always reflect the clinical setting in Dutch daily practice. However, the data were derived from patients treated under the same conditions in a trial setting, allowing these treatments to be more easily compared than when using real-world data. Additionally, the trials that provided the model inputs were similar in terms of baseline characteristics and prognosis $[11,14-16]$, which is not often the case with real-word data, where confounding by indication is a risk, particularly in oncology.

Currently, data from clinical trials are the best available evidence for comparative effectiveness of treatments for mCRPC patients in the Netherlands. Therefore, the indirect treatment comparison by means of a network meta-analysis was the best option is this situation, as it combined direct and indirect evidence on the relative treatment effects while minimising bias. When real-world patient data become available, the analysis could be updated to estimate the cost effectiveness of AA, CA, EN and Ra-223 based on patientlevel data, with caution applied to the interpretation of such results given the limitations associated with real-world data.

\section{Conclusion}

To conclude, radium-223 may be a less costly treatment strategy offering similar gains in health benefits compared with abiraterone, cabazitaxel and enzalutamide in mCRPC patients previously treated with docetaxel from the Dutch societal perspective. 
Author Contributions MLP was involved in the acquisition, analysis and interpretation of the data and the drafting and revision of the manuscript; CM was involved in the design of the study, the acquisition, analysis and interpretation of the data and the revision of the manuscript; DW, WN, AML-K, JB and HPB were involved in the data acquisition, interpretation of the data, drafting of the manuscript and the revision of the manuscript; $\mathrm{AB}$ was involved the acquisition, analysis and interpretation of the data and the drafting of the manuscript; and JGG was involved in the design of the study, the acquisition, analysis and interpretation of the data and the drafting and revision of the manuscript.

\section{Compliance with Ethical Standards}

Funding Mapi Group was financially supported by Bayer B. V. to perform the study.

Conflict of interest M. L. Peters and J. G. Gaultney are Mapi Group employees and served as paid consultants to Bayer during the conduct of this study; A. Baka was a Mapi Group employee at the time of the study and served as a paid consultant to Bayer during the conduct of this study; C. de Meijer is a Bayer employee; D. Wyndaele was consulted by Bayer in advisory boards; W. Noordzij was consulted by Bayer in an advisory board; A. M. Leliveld-Kors was consulted by Bayer and Astellas in advisory boards; J. van den Bosch was consulted by Bayer in advisory boards; and H. P. van den Berg was consulted by Bayer in advisory boards.

Open Access This article is distributed under the terms of the Creative Commons Attribution-NonCommercial 4.0 International License (http://creativecommons.org/licenses/by-nc/4.0/), which permits any noncommercial use, duplication, adaptation, distribution and reproduction in any medium or format, as long as you give appropriate credit to the original author(s) and the source, a link is provided to the Creative Commons license and any changes made are indicated.

\section{References}

1. Kirby M, Hirst C, Crawford ED. Characterising the castrationresistant prostate cancer population: a systematic review. Int $\mathrm{J}$ Clin Pract. 2011;65(11):1180-92. doi:10.1111/j.1742-1241.2011. 02799.x.

2. Scher HI, Halabi S, Tannock I, Morris M, Sternberg CN, Carducci MA, et al. Design and end points of clinical trials for patients with progressive prostate cancer and castrate levels of testosterone: recommendations of the Prostate Cancer Clinical Trials Working Group. J Clin Oncol. 2008;26(7):1148-59. doi:10.1200/jco.2007.12.4487.

3. Integraal Kankercentrum Nederland. Prostaatcarcinoom: Landelijke Richtlijn, Versie: 2.0.; 2014.

4. Mottet N (Chair), Briers E (Patient Representative), Bolla M, Cornford P (Vice-chair), De Santis M, et al. Guideline prostate cancer. European Association of Urology. 2016. http://uroweb. org/guideline/prostate-cancer/. Accessed 25 Aug 2017.

5. Body JJ, Casimiro S, Costa L. Targeting bone metastases in prostate cancer: improving clinical outcome. Nat Rev Urol. 2015;12(6):340-56. doi:10.1038/nrurol.2015.90.

6. Integraal Kankercentrum Nederland. Nederlandse Kankerregistratie. http://www.cijfersoverkanker.nl/. Accessed 14 Dec 2015.

7. Batman E, de Wit R. Effective chemotherapy for hormone-refractory prostate cancer: docetaxel-prednisone. Ned Tijdschr Geneeskd. 2005;149(44):2442-5.
8. Heidenreich A, Bastian PJ, Bellmunt J, Bolla M, Joniau S, van der Kwast T, et al. EAU guidelines on prostate cancer. Part II: treatment of advanced, relapsing, and castration-resistant prostate cancer. Eur Urol. 2014;65(2):467-79. doi:10.1016/j.eururo.2013. 11.002 .

9. Shore N, Mason M, de Reijke TM. New developments in castrate-resistant prostate cancer. BJU Int. 2012;109(Suppl. 6):22-32. doi:10.1111/j.1464-410X.2012.11217.x.

10. European Medicines Agency. Xofigo, INN radium-223 dichloride: summary of product characteristics. http://www.ema.europa. eu/docs/en_GB/document_library/EPAR_Product_Information/ human/002653/WC500156172.pdf. Accessed 15 Dec 2015.

11. Parker C, Nilsson S, Heinrich D, Helle SI, O'Sullivan JM, Fossa $\mathrm{SD}$, et al. Alpha emitter radium-223 and survival in metastatic prostate cancer. N Engl J Med. 2013;369(3):213-23. doi:10.1056/ NEJMoa1213755.

12. Cislo P, Sartor O, Reuning-Scherer J, Shan M, Zhan L, Parker C. 673 Effects of radium-223 dichloride (Ra-223) on health-related quality of life (HRQoL) assessed by the EQ-5D utility scores in ALSYMPCA. Eur Urol Suppl. 2015;14(2):e673. doi:10.1016/ S1569-9056(15)60666-2.

13. Nilsson S, Cislo P, Sartor O, Vogelzang NJ, Coleman RE, O'Sullivan JM, et al. Patient-reported quality-of-life analysis of radium-223 dichloride from the phase III ALSYMPCA study. Ann Oncol. 2016;27(5):868-74. doi:10.1093/annonc/mdw065.

14. Fizazi K, Scher HI, Molina A, Logothetis CJ, Chi KN, Jones RJ, et al. Abiraterone acetate for treatment of metastatic castrationresistant prostate cancer: final overall survival analysis of the COU-AA-301 randomised, double-blind, placebo-controlled phase 3 study. Lancet Oncol. 2012;13(10):983-92. doi:10.1016/ S1470-2045(12)70379-0.

15. de Bono JS, Oudard S, Ozguroglu M, Hansen S, Machiels JP, Kocak I, et al. Prednisone plus cabazitaxel or mitoxantrone for metastatic castration-resistant prostate cancer progressing after docetaxel treatment: a randomised open-label trial. Lancet. 2010;376(9747):1147-54. doi:10.1016/S0140-6736(10)61389-X.

16. Scher HI, Fizazi K, Saad F, Taplin ME, Sternberg CN, Miller K, et al. Increased survival with enzalutamide in prostate cancer after chemotherapy. N Engl J Med. 2012;367(13):1187-97. doi:10.1056/NEJMoa1207506.

17. Tax SEM, Scheres EAG, van der Hoeven JJM. Effectieve nieuwe middelen tegen kanker, maar het financieringssysteem kraakt. Belemmeringen en oplossingen bij de inzet van dure geneesmiddelen tegen kanker. Amsterdam: KWF Kankerbestrijding; 2015.

18. Vemer P, Corro Ramos I, van Voorn GA, Al MJ, Feenstra TL. AdViSHE: a validation-assessment tool of health-economic models for decision makers and model users. Pharmacoeconomics. 2016;34(4):349-61. doi:10.1007/s40273-015-0327-2.

19. European Medicines Agency. Xofigo, INN Radium-223 dichloride: assessment report. 2013. http://www.ema.europa.eu/docs/ en_GB/document_library/EPAR__Public_assessment_report/human/ 002653/WC500156174.pdf. Accessed 15 Dec 2015.

20. Sartor O, Coleman R, Nilsson S, Heinrich D, Helle SI, O'Sullivan $\mathrm{JM}$, et al. Effect of radium-223 dichloride on symptomatic skeletal events in patients with castration-resistant prostate cancer and bone metastases: results from a phase 3 , double-blind, randomised trial. Lancet Oncol. 2014;15(7):738-46. doi:10.1016/ s1470-2045(14)70183-4.

21. Logothetis CJ, Basch E, Molina A, Fizazi K, North SA, Chi KN, et al. Effect of abiraterone acetate and prednisone compared with placebo and prednisone on pain control and skeletal-related events in patients with metastatic castration-resistant prostate cancer: exploratory analysis of data from the COU-AA-301 randomised trial. Lancet Oncol. 2012;13(12):1210-7. doi:10. 1016/S1470-2045(12)70473-4. 
22. Fizazi K, Scher HI, Miller K, Basch E, Sternberg CN, Cella D, et al. Effect of enzalutamide on time to first skeletal-related event, pain, and quality of life in men with castration-resistant prostate cancer: results from the randomised, phase 3 AFFIRM trial. Lancet Oncol. 2014;15(10):1147-56. doi:10.1016/s14702045(14)70303-1.

23. Cherny NI, Sullivan R, Dafni U, Kerst JM, Sobrero A, Zielinski $\mathrm{C}$, et al. A standardised, generic, validated approach to stratify the magnitude of clinical benefit that can be anticipated from anticancer therapies: the European Society for Medical Oncology Magnitude of Clinical Benefit Scale (ESMO-MCBS). Ann Oncol. 2015;26(8):1547-73. doi:10.1093/annonc/mdv249.

24. Centraal Bureau voor de Statistiek. Consumentenprijzen. http:// statline.cbs.nl/Statweb/publication/?DM=SLNL\&PA=70936NED\& D1 $=0 \& D 2=493,506,519,532,545,558,571,584,597,610,623,636$, $649,662,675,688,701,1 \& H D R=T \& S T B=G 1 \& V W=T$. Accessed $4 \mathrm{Jul} 2017$.

25. The Netherlands Organisation for Health Research and Development (ZonMw). Patient reported outcomes in the CAstrationresistant Prostate cancer RegIstry (CAPRI). http://www.zonmw. nl/nl/over-zonmw/innovatie-in-de-zorg/programmas/project-detail/ goed-gebruik-geneesmiddelen/patient-reported-outcomes-in-thecastration-resistant-prostate-cancer-registry-capri/. Accessed 25 Aug 2017.

26. z-index. 2014. http://www.z-index.nl/g-standaard. Accessed 25 Aug 2017.

27. Tarieflijst instellingen juni 2014. Nederlandse Zorgautoriteit (NZa). http://www.nza.nl/regelgeving/tarieven/. Accessed 25 Aug 2017.

28. Hakkaart-van Roijen L, Tan SS, Bouwmans CAM. Handleiding voor kostenonderzoek: methoden en standaard kostprijzen voor economische evaluaties in de gezondheidszorg. Diemen: College voor Zorgverzekeringen; 2010.

29. College voor Zorgverzekeringen. $\mathrm{CFH}$-rapport abirateron $\left(\right.$ Zytiga $\left.^{\circledR}\right) ; 2012$.

30. Carter JA, Joshi A, Kaura S, Botteman MF. Cost effectiveness of zoledronic acid in the management of skeletal metastases in hormone-refractory prostate cancer patients in France, Germany, Portugal, and the Netherlands. J Med Econ. 2011;14(3):288-98. doi:10.3111/13696998.2011.570170.

31. Meeussen K, Van den Block L, Echteld MA, Boffin N, Bilsen J, Van Casteren V, et al. End-of-life care and circumstances of death in patients dying as a result of cancer in Belgium and the Netherlands: a retrospective comparative study. J Clin Oncol. 2011;29(32):4327-34. doi:10.1200/JCO.2011.34.9498.

32. Richtlijn voor het uivoeren van economische evaluaties in de gezondheidszorg. Diemen: Zorginstituut Nederland; 2015.

33. College voor Zorgverzekeringen. Pakketbeheer in de Praktijk 2. 2009. http://www.rijksoverheid.nl/binaries/rijksoverheid/document en/kamerstukken/2009/06/25/rapport-pakketbeheer-in-de-praktijk2/z-2963629c.pdf. Accessed 25 Aug 2017.

34. Middelen CBO. Systematische beoordeling van oncologische middelen. Med Oncol. 2012;1:26-9.

35. Zhong L, Pon V, Srinivas S, Nguyen N, Frear M, Kwon S, et al. Therapeutic options in docetaxel-refractory metastatic castrationresistant prostate cancer: a cost-effectiveness analysis. PLoS One. 2013;8(5):e64275. doi:10.1371/journal.pone.0064275.

36. Obando CA, Desanvicente-Celis Z, Gonzalez L, Muschett D, Gonzalez F, Goldberg P. Cost-effectiveness analysis of abiraterone acetate treatment compared with cabacitaxel in dominican republic, in patients with metastatic castration-resistant prostate cancer that have failed to chemotherapy with docetaxel. Value Health. 2014;17(7):A635. doi:10.1016/j.jval.2014. 08.2279

37. Obando CA, Desanvicente-Celis Z, Gonzalez L, Muschett D, Gonzalez F, Goldberg P. Cost-effectiveness analysis of abiraterone acetate treatment compared with cabacitaxel in the republic of panama, in patients with metastatic castration-resistant prostate cancer that have failed to chemotherapy with docetaxel. Value Health. 2014;17(7):A632. doi:10.1016/j.jval.2014. 08.2261.

38. Vicente C, Babashov V, Husein F, Saad F, Naidoo S, Holmstrom S. Cost-utility analysis of enzalutamide for patients with previously treated metastatic castration-resistant prostate cancer (MCRPC). Value Health. 2014;17(3):A89-90. doi:10.1016/j.jval. 2014.03.521.

39. Thompson M, Li T, Todd MB, Yu MK, Kheoh T, He J, et al. An indirect treatment comparison and costeffectiveness analysis of abiraterone acetate and enzalutamide for the treatment of metastatic castration-resistant prostate cancer post chemotherapy. J Urol. 2014;1:e811. doi:10.1016/j.juro.2014.02.2211.

40. Shibahara H, Shiroiwa T, Nakamura K, Shimozuma K. Costeffectiveness analysis of abiraterone acetate as second line treatment for metastatic castration-resistant prostate cancer after docetaxel treatment in Japan. Value Health. 2013;16(7):A415-6. doi:10.1016/j.jval.2013.08.532.

41. Kostyuk A, Almadiyeva A. Pharmacoeconomic evaluation of abiraterone ac etate versus cabazitaxel in the treatment of metastatic castration-resistant prostate cancer in Kazakhstan. Value Health. 2013;16(7):A412. doi:10.1016/j.jval.2013.08.513.

42. He J, Li T, Saadi R. Abiraterone acetate versus enzalutamide for metastatic castration-resistant prostate cancer post chemotherapy: cost effectiveness analysis. Value Health. 2013;16(7):A411. doi:10.1016/j.jval.2013.08.506.

43. Yeung K, Gong CL. Cost-utility analysis of enzalutamide versus abiraterone for the treatment of docetaxel refractory metastatic castrate resistant prostate cancer. Value Health. 2013;16(3):A143. doi:10.1016/j.jval.2013.03.701.

44. Joulain F, Zavisic S, Mehta J. Cabazitaxel in second line (2l) treatment of metastatic castration resistant prostate cancer: an economic evaluation in Sweden. Value Health. 2013;16(3):A138. doi:10.1016/j.jval.2013.03.676.

45. Persson U, Nilsson S, Prutz C, Hjortsberg C. Cost effectiveness analysis of abiraterone acetate as treatment for metastatic castration resistant prostate cancer after failure of docetaxel using data from real life treatment praxis in Sweden. Value Health. 2013;16(3):A134-5. doi:10.1016/j.jval.2013.03.655.

46. Zhong L, Srinivas S, Pon V, Nguyen N, Frear M, Kwan S, et al. Therapeutic options in metastatic castration-resistant prostate cancer (mCRPC): a cost-effectiveness analysis. J Clin Oncol. 2012;30(Suppl):e15154.

47. Pereira ML, Bahmdouni LSK, Pepe C, Teich V. Cost-effectiveness analysis of abiraterone for the treatment of advanced prostate cancer under the brazilian private health care system. Value Health. 2012;15(7):A424-5. doi:10.1016/j.jval.2012.08.2126.

48. Efstathiou E, Gyftaki R, Kousoulakou H, Paparouni K, Ikonomou V. Abiraterone acetate versus cabazitaxel in the treatment of metastatic castration-resistant prostate cancer: an economic evaluation in the Greek health care setting. Value Health. 2012;15(7):A424. doi:10.1016/j.jval.2012.08.2124.

49. Ostale S, Ruiz P. Cost-efficacy analysis of licensed drugs for the treatment of metastatic castrate resistant prostate cancer post docetaxel based on hospital drug evaluation methodology in Spain. Value Health. 2012;15(7):A417. doi:10.1016/j.jval.2012. 08.1239.

50. Persson U, Nilsson S, Hjortsberg C, Prutz C. Economic evaluation of abiraterone acetate as treatment for metastatic castration resistant prostate cancer after failure of docetaxel in Sweden. Value Health. 2012;15(4):A219. doi:10.1016/j.jval.2012.03.1183.

51. College voor Zorgverzekeringen. CFH rapport cabazitaxel (Jevtana). 2011. 
52. Umeweni N, Knight H, McVeigh G. NICE guidance on radium223 dichloride for hormone-relapsed prostate cancer with bone metastases. Lancet Oncol. 2016;17(3):275-362. doi:10.1016/ S1470-2045(16)00060-7.
53. National Institute for Health and Care Excellence. Radium-223 dichloride for treating hormone-relapsed prostate cancer with bone metastases, Technology Appraisal Guidance (TA412). London: NICE; 2016. 